\title{
Thermodynamic Modeling of Ni-Si-Cr-B-C System in Air and Propane Atmosphere
}

\author{
Nina Ilinykh ${ }^{1,{ }^{*}}$, Anastasia Krivorigova ${ }^{1,2}$, Boris Gelchinski ${ }^{1}$, and Sergey Ilinykh $^{1}$ \\ ${ }^{1}$ Institute of Metallurgy of the Ural Branch of the Russian Academy of Sciences, 101, Amundsen Str., \\ Ekaterinburg, Russia, 620016 \\ ${ }^{2}$ Ural Institute of State Fire Service of EMERCOM of Russia, 22 Mira Str., Ekaterinburg, Russia
}

\begin{abstract}
Thermodynamic modeling of a powder self-fluxing material PGSR-2 based on nickel (wt. \%): Ni-79.3, C-0.5, Cr-15, Si-3.2, B-2 was carried out. Modeling was executed in the temperature range of 300-6000 $\mathrm{K}$ in the atmosphere of air and gas mixture "92 vol. \% air +8 vol. \% propane" at a total pressure of $\mathrm{P}=10^{5} \mathrm{~Pa}$. The temperature dependences of the equilibrium composition of the condensed and gas phases formed during the heating of the investigated system were calculated. It is shown that the distribution of the components of the condensed and gas phases changes significantly when the initial content of the powder material and the composition of the plasma-forming gas are changed.
\end{abstract}

\section{Introduction}

To restore the geometric dimensions and shape of the surfaces of the wear parts, gasthermal coating methods are used, among which the most common is plasma powder spraying [1-10]. This method provides high performance and versatility, as well as a wide range of coatings properties. Powder self-fluxing materials are widely used for the restoration of worn surfaces by sputtering and sputtering with reflow [6, 9-14]. The most common of them are self-fluxing alloys of the Ni-Cr-Si-B system. The processability of these alloys is due to the formation of a heterogeneous structure of the eutectic type with a characteristic low melting point (approximately $1000^{\circ} \mathrm{C}$ ) [9]. The coatings formed during the surfacing of these powder materials have high hardness and wear resistance due to the formation of fine particles of strengthening phases, such as $\mathrm{CrB}, \mathrm{Cr}_{23} \mathrm{C}_{6}, \mathrm{Cr}_{7} \mathrm{C}_{3}$ and others $[10,11]$. To obtain composite alloys with higher physical and mechanical properties, carbides and borides of refractory metals (tungsten, vanadium, chromium and molybdenum) are often added.

The composition, structure, and content of the components, as well as the integral physicochemical properties of the new materials, depend on the initial ratio of the elements, parameters, and the degree of nonequilibrium of the system under study (heating and cooling rates, temperature gradients, and other technological factors). When spraying gasthermal coatings, it is often necessary to vary the input parameters: the initial composition of the powder material and the plasma-forming gas, temperature, pressure, etc. The choice

* Corresponding author: ninail@bk.ru 
of these parameters can be greatly facilitated by thermodynamic calculations. These calculations can significantly reduce the amount of experimental research, time and material costs. For equilibrium (quasi-equilibrium) processes, the implementation of thermodynamic calculations is a necessary stage of research. In the case of nonequilibrium processes, thermodynamic calculations allow us to estimate the limit values of various process parameters.

The aim of this work is thermodynamic modeling of the equilibrium composition and thermodynamic characteristics of self-fluxing $\mathrm{Ni}-\mathrm{C}-\mathrm{Cr}-\mathrm{Si}-\mathrm{B}$ powder materials in a wide temperature range in the atmosphere of air and propane.

\section{Method of investigation}

The computer experiment was carried out using of the thermodynamic modeling method (TM) [15-19].

The TERRA software package was used as the modeling software [15-18]. This software implements the method and algorithm of calculations created at the Bauman Moscow State Technical University. It is designed to calculate arbitrary systems with chemical and phase transformations and allows us to model extremely equilibrium states. The TERRA program is coupled with an extensive database of properties of individual substances, which makes it suitable for the study of arbitrary chemical compositions. The maximum number of chemical elements that can make up the system under study is fifty; the number of condensed phases considered in a single calculation is limited to two hundred, and the number of components of the gas phase formed in equilibrium (the number of individual substances) can reach eight hundred. When performing calculations for heterogeneous systems, it is possible to use both models of single-component immiscible phases and various models of condensed solutions.

The simulation was carried out in the temperature range of 300-6000 $\mathrm{K}$ at a total pressure of $\mathrm{P}=105 \mathrm{~Pa}$ in the atmosphere of the plasma-forming gas. Air and a mixture of "92\% air $+8 \%$ propane" (vol. $\%$ ) were considered as plasma-forming gases. The initial composition of the simulated system corresponded to the composition of the powder selffluxing material PGSR-2 based on nickel (wt.\%): Ni - 79.3, C - 0.5, Cr - 15, Si - 3.2, B - 2. When preparing the initial data for modeling, the average technological parameters of the plasma spraying plant were taken into account: the flow rate of the plasma-forming gas - 1 $1 / \mathrm{s}$, the flow rate of the powder $-1 \mathrm{~g} / \mathrm{s}, 5 \mathrm{~g} / \mathrm{s}$ and $10 \mathrm{~g} / \mathrm{s}$.

\section{Results and discussion}

\subsection{Simulation of PGSR-2 heating in air}

Fig.1 shows the temperature dependences of the content of the components of the condensed phase formed during the equilibrium heating of PGSR-2 in the air atmosphere at different powder flow rates: $1 \mathrm{~g} / \mathrm{s}(\mathrm{a}), 5 \mathrm{~g} / \mathrm{s}$ (b) and $10 \mathrm{~g} / \mathrm{c}$ (c).

It can be seen from Fig. 1-a, that at the initial composition of the simulated system, corresponding to the flow rate of the plasma - forming gas of $1 \mathrm{l} / \mathrm{s}$ and the powder material$5 \mathrm{~g} / \mathrm{s}$, active oxidation occurs. The existence of carbon, nickel, and $\mathrm{NiO}, \mathrm{B}_{2} \mathrm{O}_{3}, \mathrm{SiO}_{2}$ and $\mathrm{Cr}_{2} \mathrm{O}_{3}$ oxides is possible in the condensed phase. The nickel content is constant in the temperature range of $400-2000 \mathrm{~K}$. The increasing of the mass fraction of nickel in the temperature range of $300-400 \mathrm{~K}$ and $2000-2400 \mathrm{~K}$ is due to a decrease in the mass fraction of $\mathrm{NiO}$ from 0.17 to 0.14 (at $300-400 \mathrm{~K}$ ) and from 0.14 to 0 in the range of $2000-2400 \mathrm{~K}$. 
At $\mathrm{T}=2400 \mathrm{~K}$, complete evaporation of $\mathrm{NiO}$ occurs and a sharp decrease in the mass fraction of nickel begins, due to its evaporation.
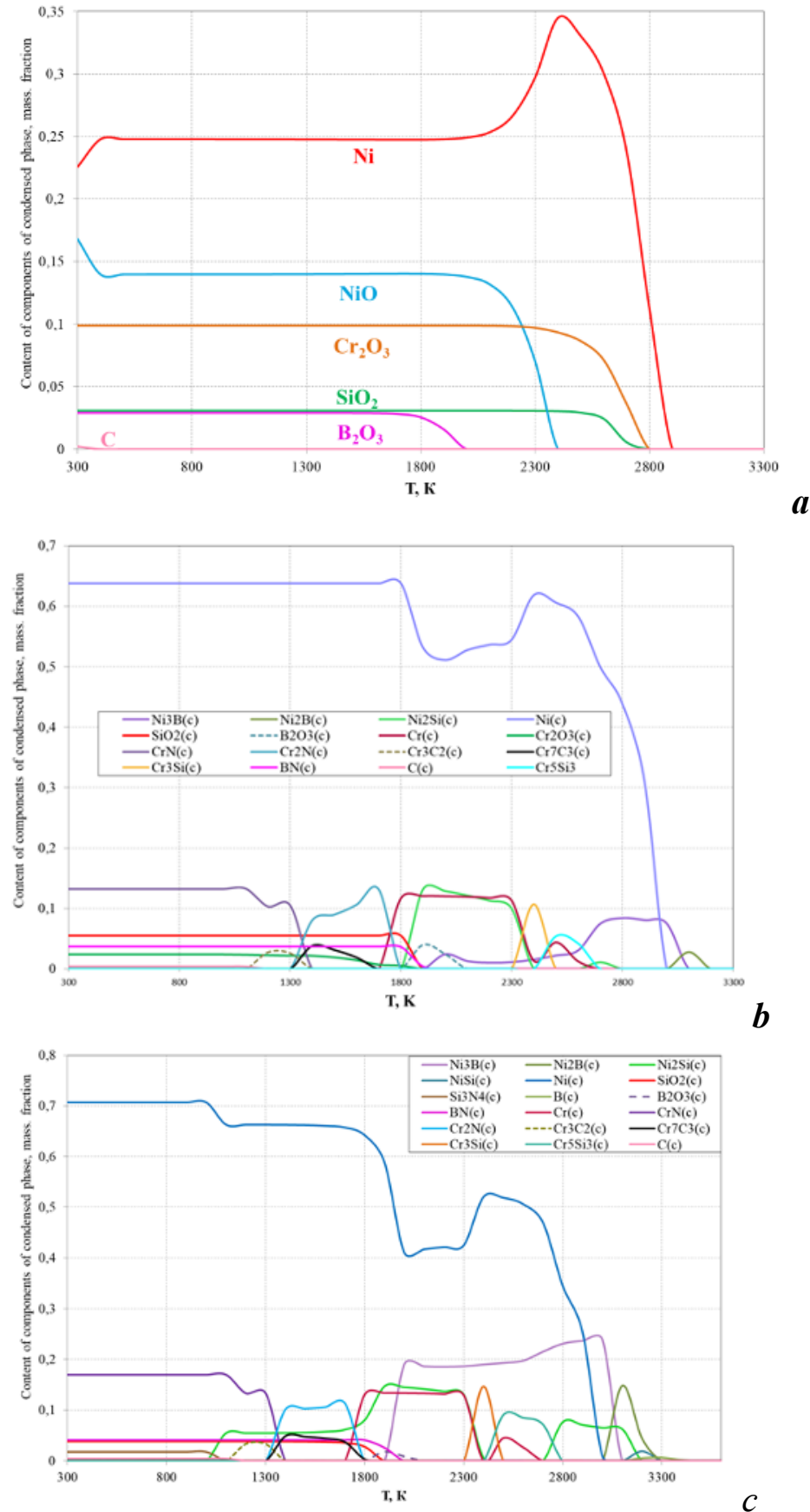

$c$

Fig. 1. Temperature dependences of the content of the components of the condensed phase formed during the equilibrium heating of PGSR-2 in the air atmosphere. Gas consumption 1 1/s. Powder material consumption: a) $1 \mathrm{~g} / \mathrm{s}$; b) $5 \mathrm{~g} / \mathrm{s}$; c) $10 \mathrm{~g} / \mathrm{s}$. 

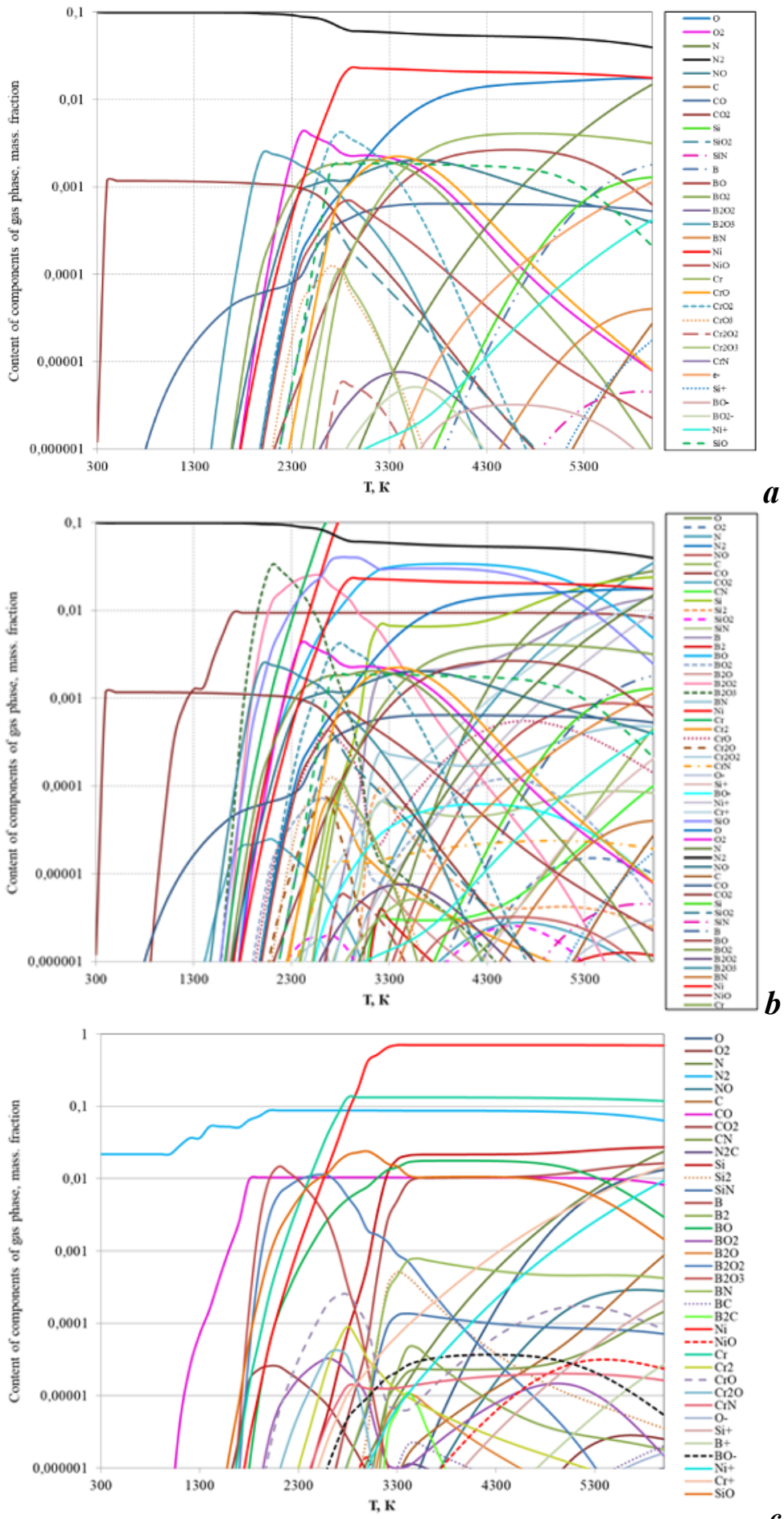

Fig. 2. Temperature dependences of the content of the components of the gas phase formed during the equilibrium heating of PGSR-2 in the air atmosphere. Gas consumption - 11/s. Powder material consumption: a) $1 \mathrm{~g} / \mathrm{s}$; b) $5 \mathrm{~g} / \mathrm{s}$; c) $10 \mathrm{~g} / \mathrm{s}$. 
With the initial compositions of the simulated system corresponding to the flow rates of the plasma - forming gas of $1 \mathrm{l} / \mathrm{s}$ and the powder material-5 g/s (Fig. 1-b) and $10 \mathrm{~g} / \mathrm{s}$ (Fig. 1c), the condensed phase may contain $\mathrm{Ni}, \mathrm{Ni}_{3} \mathrm{~B}, \mathrm{Ni}_{2} \mathrm{~B}, \mathrm{Ni}_{2} \mathrm{Si}, \mathrm{SiO}_{2}, \mathrm{~B}_{2} \mathrm{O}_{3}, \mathrm{Cr}, \mathrm{CrN}, \mathrm{Cr}_{2} \mathrm{~N}$, $\mathrm{Cr}_{3} \mathrm{C}_{2}, \mathrm{Cr}_{7} \mathrm{C}_{3}, \mathrm{Cr}_{3} \mathrm{Si}, \mathrm{Cr}_{5} \mathrm{Si}_{3}, \mathrm{BN}, \mathrm{C}$. In addition, with an increase in the flow rate of the powder material in the system in the condensed phase, the appearance of boron and $\mathrm{NiSi}$, $\mathrm{Si}_{3} \mathrm{~N}_{4}$ compounds is observed.

Let us consider in detail the behavior of the components of the condensed phase on the example of Fig. 1-b. The nickel content practically does not change in the temperature range of $300-1800 \mathrm{~K}$. In the temperature range of $1800-2000 \mathrm{~K}$, a decrease in the mass fraction of nickel is observed, and at $2000-2400 \mathrm{~K}$, its increase is observed. A subsequent increase in temperature to $3000 \mathrm{~K}$ is accompanied by a sharp decrease in the mass fraction of nickel to zero. In the temperature range of 1900-3100, the formation of compounds $\mathrm{Ni}_{3} \mathrm{~B}$ (2000-3000 K), Ni 2 Si (1900-2400 K), Ni ${ }_{2} \mathrm{~B}(3100 \mathrm{~K}), \mathrm{B}_{2} \mathrm{O}_{3}(1900-2100 \mathrm{~K}), \mathrm{Cr}_{3} \mathrm{Si}(2400$ $\mathrm{K}), \mathrm{Cr}_{5} \mathrm{Si}_{3}(2500-2600 \mathrm{~K})$ is possible. The $\mathrm{CrN}$ content is almost constant in the temperature range of 300-1100 K, at 1100-1300 K non-monotonic behavior is observed due to the formation of $\mathrm{Cr}_{3} \mathrm{C}_{2}$, and at 1300-1400 - a sharp decrease to zero. The compounds $\mathrm{Cr}_{2} \mathrm{~N}$ and $\mathrm{Cr}_{7} \mathrm{C}_{3}$ exist in the temperature range of 1400-1700 K. The content of $\mathrm{SiO}_{2}, \mathrm{BN}$, $\mathrm{Cr}_{2} \mathrm{O}_{3}$, and $\mathrm{C}$ is almost unchanged over a wide temperature range: $300-1800\left(\mathrm{SiO}_{2}\right.$ and $\mathrm{BN}), 300-1300 \mathrm{~K}(\mathrm{CrN}), 300-1000(\mathrm{C})$, and 300-1400 $\mathrm{K}\left(\mathrm{Cr}_{2} \mathrm{O}_{3}\right)$. At $\mathrm{T} \geq 1700 \mathrm{~K}$ the decomposition of the compounds $\mathrm{Cr}_{2} \mathrm{O}_{3}, \mathrm{Cr}_{7} \mathrm{C}_{3}, \mathrm{Cr}_{3} \mathrm{C}_{2}, \mathrm{CrN}, \mathrm{Cr}_{3} \mathrm{Si}$ occurs, so the existence of condensed $\mathrm{Cr}$ is observed in the temperature range $1800-2600 \mathrm{~K}$.

Figure 2 shows the temperature dependences of the content of the components of the gas phase formed during the equilibrium heating of PGSR-2 in the air atmosphere. The main components of the gas phase in the temperature range of $300-1800 \mathrm{~K}$ are $\mathrm{N}_{2}, \mathrm{CO}$ and $\mathrm{CO}_{2}$, the content of the other components is significantly lower. The temperature increase is accompanied by the evaporation of the condensed phase components (see Fig. 1) and an increase in the vapor content of nickel, chromium, silicon, boron, their oxides, and nitrides in the gas phase. A subsequent increase of temperature leads to the dissociation of $\mathrm{N}_{2}, \mathrm{O}_{2}$, $\mathrm{CO}_{2}, \mathrm{SiO}_{2}, \mathrm{~B}_{2} \mathrm{O}_{3}, \mathrm{NiO}$ and other molecules, which leads to an increase in the mass fraction (and, accordingly, the partial pressures) of atomic oxygen, nitrogen, boron, nickel, silicon, etc. The content of ionized components of the gas phase $\left(\mathrm{Ni}^{+}, \mathrm{Si}^{+}, \mathrm{Cr}^{+}, \mathrm{BO}^{-}, \mathrm{BO}_{2}^{-}, \mathrm{O}^{-}\right)$in the investigated temperature range is small.

\subsection{Simulation of PGSR-2 heating in the atmosphere "air + propane»}

Figure 3 shows the temperature dependences of the content of the components of the condensed and gas phases formed during the equilibrium heating of PGSR-2 in the atmosphere of the plasma-forming gas "92 vol.\% air+8 vol.\% propane". When preparing the initial data for modeling, the technological parameters of the plasma spraying installation were taken into account: the flow rate of plasma-forming gas $-11 / \mathrm{s}$, the flow rate of powder $-1 \mathrm{~g} / \mathrm{s}$.

As can be seen from Fig. 3-a, the existence of $\mathrm{Ni}, \mathrm{Cr}, \mathrm{C}, \mathrm{Ni}_{2} \mathrm{Si}, \mathrm{B}_{2} \mathrm{O}_{3}, \mathrm{BN}, \mathrm{Cr}_{2} \mathrm{O}_{3}, \mathrm{SiO}_{2}$, $\mathrm{HBO}_{2}, \mathrm{Cr}_{3} \mathrm{C}_{2}, \mathrm{Cr}_{7} \mathrm{C}_{3}$ is possible in the condensed phase. The content of other components is insignificant (less than $0.01 \mathrm{wt}$. \%). The nickel content is constant in the temperature range of $300-2300 \mathrm{~K}$. The decrease in the mass fraction of nickel at $\mathrm{T}=1900 \mathrm{~K}$ is caused with the formation of the $\mathrm{Ni}_{2} \mathrm{Si}$ compound, which exists in a narrow temperature range of 1900-2000 K. Chromium oxide $\mathrm{Cr}_{2} \mathrm{O}_{3}$ is stable in the temperature range of $300-1400 \mathrm{~K}$. With a following increase of temperature, the content of $\mathrm{Cr}_{2} \mathrm{O}_{3}$ decreases, while in the temperature range of 1300-1500 K, the formation of $\mathrm{Cr}_{3} \mathrm{C}_{2}$ chromium carbide is observed, and in the temperature range of $1500-1900 \mathrm{~K}-\mathrm{Cr}_{7} \mathrm{C}_{3}$ chromium carbide. At $\mathrm{T} \geq 1800$, the content of $\mathrm{Cr}_{7} \mathrm{C}_{3}$ decreases sharply, while the appearance of chromium is observed in the 
condensed phase at $1900-2400 \mathrm{~K}$. Silicon oxide in the condensed phase exists in the temperature range of 300-2100 K, and, in the temperature range of 300-1800 K, the $\mathrm{SiO}_{2}$ content is unchanged. In addition, $\mathrm{HBO}_{2}, \mathrm{~B}_{2} \mathrm{O}_{3}$, and $\mathrm{C}$ can be formed in the condensed phase. The content of these components is less than $0.05 \mathrm{wt} . \%$.

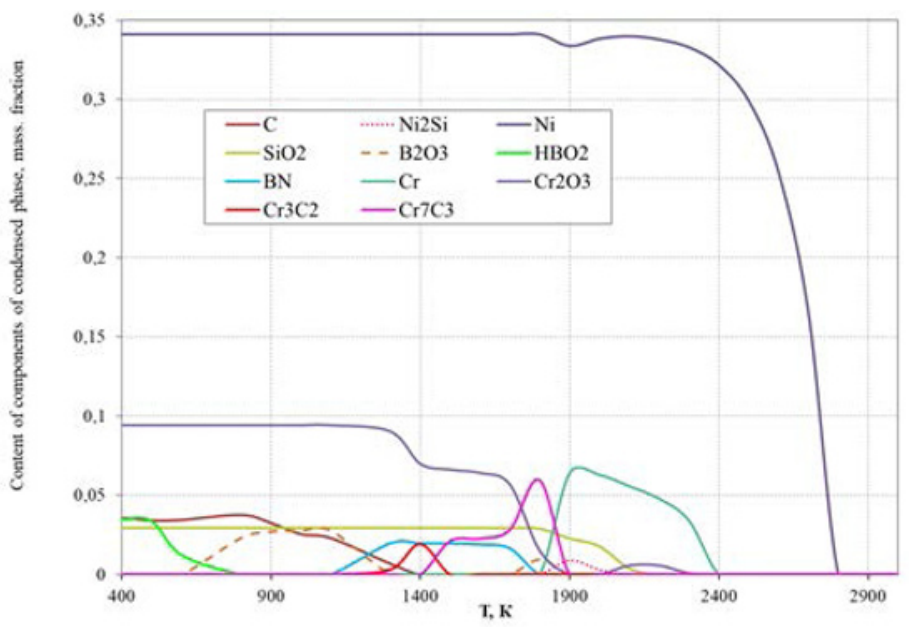

$\boldsymbol{a}$

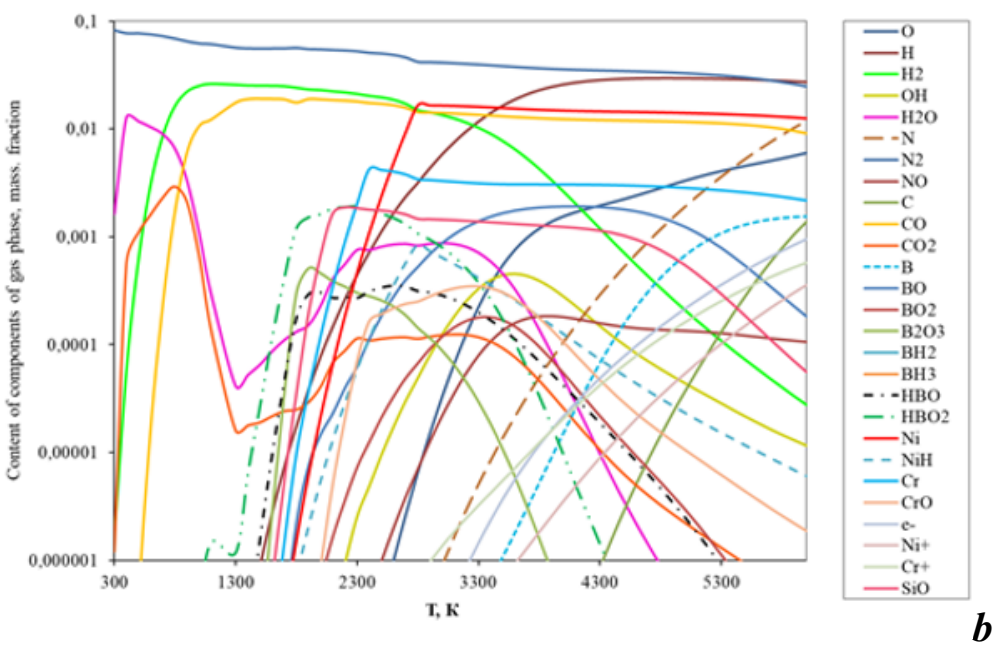

Fig. 3. Temperature dependences of the content of the components of the condensed (a) and gas phases (b) formed during the equilibrium heating of the PGSR-2 system in the atmosphere "92 vol.\% air +8 vol. $\%$ propane».

The main components of the gas phase (Fig. 3-b) in the entire studied temperature range are $\mathrm{N}_{2}, \mathrm{H}_{2}, \mathrm{CO}, \mathrm{H}_{2} \mathrm{O}$, and $\mathrm{CO}_{2}$. The mass fraction of $\mathrm{H}_{2}, \mathrm{CO}, \mathrm{H}_{2} \mathrm{O}$, and $\mathrm{CO}_{2}$ change nonmonotonically with increasing of temperature, and the pressure of $\mathrm{N}_{2}$ decreases monotonically. The contribution of the other components of the gas phase to the total content becomes noticeable at $\mathrm{T} \geq 1300 \mathrm{~K}$. It should be noted that in the studied temperature range, the main ionized components of the gas phase are the electron gas $\mathrm{e}^{-}$, as well as the $\mathrm{Ni}^{+}$and $\mathrm{Cr}^{+}$ions. 


\section{Conclusion}

Thermodynamic modeling of a powder self-fluxing material PGSR-2 based on nickel (wt.\%): Ni-79.3, C-0.5, Cr-15, Si-3.2, B-2 in the temperature range of 300-6000 $\mathrm{K}$ in the atmosphere of air and gas mixture "92 vol. $\%$ air +8 vol. $\%$ propane" at a total pressure of $\mathrm{P}=10^{5} \mathrm{~Pa}$ was carried out.

It is shown that the distribution of the components of the condensed and gas phases changes significantly with changes in the initial content of the powder material and the composition of the plasma-forming gas:

- When simulating the heating of PGSR-2 in an air atmosphere with the initial composition corresponding to the flow rate of the plasma-forming gas of $1 \mathrm{l} / \mathrm{s}$ and the powder material of $5 \mathrm{~g} / \mathrm{s}$, active oxidation occurs. In the condensed phase, the existence of carbon, nickel and oxides of $\mathrm{NiO}, \mathrm{B}_{2} \mathrm{O}_{3}, \mathrm{SiO}_{2}, \mathrm{Cr}_{2} \mathrm{O}_{3}$ is possible.

- When simulating the heating of PGSR-2 in an air atmosphere with the initial composition corresponding to the flow rate of the plasma-forming gas of $1 \mathrm{l} / \mathrm{s}$, and the powder material of 5 (10) g/s, the formation of Ni, Ni3B, Ni2B, Ni2Si, SiO2, B2O3, $\mathrm{Cr}, \mathrm{CrN}, \mathrm{Cr}_{2} \mathrm{~N}, \mathrm{Cr}_{3} \mathrm{C}_{2}, \mathrm{Cr}_{7} \mathrm{C}_{3}, \mathrm{Cr}_{3} \mathrm{Si}, \mathrm{Cr}_{5} \mathrm{Si}_{3}, \mathrm{C}, \mathrm{BN}$ is possible in the condensed phase. With an increase in the consumption of powder material in the condensed phase, the appearance of $\mathrm{NiSi}, \mathrm{Si}_{3} \mathrm{~N}_{4}$ compounds and boron is observed.

- When PGSR-2 is heated in air, the main components of the gas phase in the temperature range of $300-1800 \mathrm{~K}$ are $\mathrm{N}_{2}, \mathrm{CO}$ and $\mathrm{CO}_{2}$, the content of the other components is significantly lower. The increase of temperature is accompanied by the evaporation of the components of the condensed phase and an increase in the vapor content of nickel, chromium, silicon, boron, their oxides, nitrides in the gas phase, as well as to the dissociation of molecules and ionization of the gas.

- At the equilibrium heating of PGSR-2 in the atmosphere of "92 vol.\% air+8 vol.\% propane" in the condensed phase, the existence of $\mathrm{Ni}, \mathrm{Cr}, \mathrm{C}, \mathrm{Ni}_{2} \mathrm{Si}, \mathrm{B}_{2} \mathrm{O}_{3}, \mathrm{BN}, \mathrm{Cr}_{2} \mathrm{O}_{3}$, $\mathrm{SiO}_{2}, \mathrm{HBO}_{2}, \mathrm{Cr}_{3} \mathrm{C}_{2}, \mathrm{Cr}_{7} \mathrm{C}_{3}$ is possible. The main components of the gas phase in the entire temperature range under study are $\mathrm{N}_{2}, \mathrm{H}_{2}, \mathrm{CO}, \mathrm{H}_{2} \mathrm{O}$ and $\mathrm{CO}_{2}$.

Thus, the results obtained allow us to estimate the composition of the condensed and gas phases formed during the equilibrium heating of the studied system, and to predict the behavior of materials under extreme conditions. It should be noted that the methods and calculation algorithms used by us are intended for modeling extremely equilibrium states of complex systems and do not allow us to find the "trajectory" of the transition to the equilibrium state.

The reported study was funded by RFBR, project number №20-21-00063 Rosatom

\section{References}

1. I. Khasui, O. Morigaki, Hard Facing and Sputtering (Mashinostroenie, Moscow, 1985) (in Russian)

2. I. Khasui, Spraying technique (Mashinostroenie, Moscow, 1975) (in Russian)

3. V.V. Kudinov, Plasma coatings (Nauka, Moscow, 1977) (in Russian)

4. Ju.S. Borisov, Ju.A. Charlamov, S.L. Sidorenko at al. Thermal coatings of powder materials (Naukova Dumka, Kiev, 1987) (in Russian)

5. Yu.S. Borisov, A.L. Borisova, Plasma powder coatings (Tehnika, Kiev, 1986) (in Russian) 
6. V.I. Kuzmin, S.P. Vashenko, I.P. Guljaev at al., Plasma sputtering of wear-resistant coatings made of self-fluxing alloy powders, Vestnik Jugorskogo gosudarstvennogo universiteta, v. 2(37), pp 45-52 (2015) (in Russian)

7. R.C. Tucker, Jr., Introduction to Coating Design and Processing, ASM Handbook, v.5, pp. 497-509 (1994)

8. V.A. Frolov, V.A. Poclad, B.V. Rjabenko at al. Technological features of supersonic gas thermal spraying methods (review), Svarochnoe proisvodstvo, No.11, pp. 38-47 (2006) (in Russian)

9. L.I. Tushinskii, A.V. Plochov. Тушинский, Л.И. Investigation of the structure and physical and mechanical properties of coatings (Nauka, Novosibirsk, 1986) (in Russian).

10. T.A. Zimoglyadova, H. Saage, V.A. Pasichnik, A.S. Egorova and .O. Matts, Metal Science and Heat Treatment, v. 60(9-10), pp 633-40 (2019) DOI: 10.1007/s11041019-00330-4.

11. I. Hemmati, V. Ocelı'k, Microstructure and Phase Formation in a Rapidly Solidified Laser Deposited Ni-Cr-B-Si-C Hardfacing Alloy, Metallurgical and materials transactions, No2, pp.878-892 (2014)

12. A.E. Terentyev, Investigation of the influence of the composition, production technology and method of applying a composite powder based on an alloy of the system (Ni-Cr-Si-B) on the wear resistance of gas-thermal coatings under friction conditions without lubrication, Problems of tribology, No. 1, pp. 77-83 (2014) (in Russian)

13. A.S. Krivorogova, N.I. Ilinykh, S.A. Ilinykh and B. R. Gel'chinskii, Theoretical and Experimental Study of Nickel-Based Self-Fluxing Materials, Russian Metallurgy (Metally), v.2020, No.8, pp. 853-858 DOI: 10.1134/S0036029520080091

14. Nina Ilinykh, Anastasia Krivorigova, Boris Gelchinski, Sergey Ilinykh, Leonid Kovalev, Thermodynamic modeling of composition and propereties of self-fluxing materials based on the nickel, MATEC Web of Conferences, v. 329, p. 02026 (2020) DOI: $10.1051 /$ matecconf $/ 202032902026$

15. G.B. Sinjarev N.A. Vatolin, B.G. Trusov, G.K. Moiseev. The use of IBM for the thermodynamic calculations of metallurgical processes (Nauka, Moscow, 1983) (In Russian)

16. N.A. Vatolin, G.K. Moiseev, B.G. Trusov. Thermodynamic modeling in the hightemperature inorganic systems (Metallurgia, Moscow, 1994) (In Russian)

17. B.G. Trusov, Programmatic system for modeling phase and chemical equilibria at high temperatures, Vestnik MGTU im. N.E. Baumana. Ser. Priborostroenie, pp. 240249 (2012) (In Russian)

18. G.V. Belov, B.G. Trusov, Thermodynamic modeling of chemically reacting systems (Moscow, Bauman Moscow State Technical University, 2013) (in Russian)

19. N.I. Ilinykh, T.V. Kulikova, G.K. Moiseev. Composition and equilibrium characteristics of metallic melts of binary systems based on iron, nickel and aluminum (UrO RAN, Ekaterinburg, 2006) (In Russian) 